\title{
Korelasi Tortuositas dengan Porositas Absolut dalam Pemodelan Aliran Fluida Menggunakan Lattice Gas Automata Model FHP III
}

\author{
Yoga Satria Putra ${ }^{1}$ \\ 1) Jurusan Fisika FMIPA Universitas Tanjungpura, Pontianak, \\ email : yoga_peneliti@yahoo.co.id
}

\begin{abstract}
Abstrak
Telah dihitung nilai tortuositas dan porositas absolut dalam pemodelan aliran fluida menggunakan Lattice Gas Automata model FHP III. Selanjutnya kedua sifat makroskopis tersebut (tortuositas dan porositas absolut) dikorelasikan dalam bentuk grafik. Perhitungan dan pemodelan pada penelitian ini dilakukan dengan menggunakan metoda Lattice Gas Automata (LGA).LGA adalah metode numerik pengembangan dari Cellular Automata (CA) yang dapat memecahkan persamaan dinamika fluida yang memenuhi persamaan Navier Stokes. Karakteristik dari LGA yaitu adanya suatu sistem yang terdiri dari partikel-partikel identik yang bermassa satu satuan bergerak dengan satu satuan kecepatan yang menempati kisi heksagonal dimana setiap tumbukannya memenuhi hukum kekekalan massa dan momentum. Metode ini menggunakan pendekatan diskretisasi ruang dan waktu serta mengikuti aturan tumbukan tertentu. Dalam penelitian ini model yang dipilih adalah model FHP III (Frisch, Hasslacher and Pomeau model III). Model aliran fluida dalam penelitian ini dibandingkan dengan model aliran fluida yang telah dibuat dalam penelitian-penelitian sebelumnya dan menghasilkan pola aliran yang mirip. Model aliran fluida dibangun pada medium berukuran 400x300 lattice unit (lu) dengan time steps 4000. Tortuositas dan porositas absolut dihitung dalam penelitian ini, dimana nilai tortuositas berbanding terbalik dengan porositas absolut.
\end{abstract}

Kata kunci : LGA,model aliran fluida, tortuositas, porositas absolut.

\section{Pendahuluan}

Kajian tentang aliran fluida dalam media berpori telah menarik perhatian para ilmuan. Hal ini disebabkan karena pengetahuan tentang aliran fluida dapat dimanfaatkan dalam berbagai bidang, seperti pemodelan air tanah, pemanfaatan reservoir, rekayasa material, rekayasa biomedis dan lain-lain. Para ilmuan juga telah banyak melakukan penelitian dan membuat model aliran fluida serta menentukan sifat-sifat makroskopis dari media pori dengan memanfaatkan metode numerik. Metode numerik yang digunakan di antaranya metode beda hingga atau elemen hingga untuk pemecahan persamaan Navier-Stokes [9].Salah satu metoda yang bisa diterapkan untuk memodelkan aliran fluida adalah Lattice Gas Automata(LGA). Kelebihan metoda LGA dibandingkan dengan metoda numerik lain diantaranya adalah mampu menampilkan geometri dari pola aliran fluida serta dapat menghasilkan model aliran fluida tanpa harus memecahkan persamaan hidrodinamikanya[1].

Beberapa penelitian mengenai LGA telah banyak dilakukan oleh para ilmuan. Diantaranya yang dilakukan pertama kali oleh Frisch, Hasslacher dan Pomeau pada tahun 1986. Mereka menggunakan metode LGA untuk menyelesaikan persamaan Navier-Stokes.
Kemudian pada tahun 2004, Kristanto, membuat sebuah tesis tentang model aliran fluida satu fase dan dua fase melalui media pori heterogen menggunakan LGA model FHP II. Metoda LGA juga bisa diterapkan untuk membuat animasi aliran fluida pada sebuah games ${ }^{[5]}$.

Tujuan dari penelitian ini adalah menmodelkan aliran fluida dalam media pori heterogen menggunakan metoda LGA. Selanjutnya menghitung sifat makroskopis dari media pori heterogen, yaitu porositas dan permeabilitasserta korelasi diantara kedua sifat tersebut.Hasil model dalam penelitian ini dibandingkan dengan hasil model yang telah dilakukan oleh Kristanto pada tahun 2004. Perbedaannya terletak pada model yang digunakan. Kristanto menggunakan LGA model II dalam membuat modelnya, sedangkan dalam penelitian ini yang digunakan adalah LGA model III.

\section{Tinjauan Pustaka 2.1 LGAModel FHP}

Model FHP diperkenalkan oleh Uriel Frisch, Brosl Hasslacher, dan Yves Pomeau [3].Model ini merupakan pengembangan dari model HPP yang diperkenalkan oleh Jean Hardy, Olivier de Pazzis, dan Yves Pomeau pada tahun 1973. Model HPP menggunakan kisi bujur sangkar sementara model FHP menggunakan 
kisi segitiga sama sisi. Model FHP terdiri dari partikel-partikel yang bergerak dari satu sel ke sel lain dalam kisi segitiga. Dalam kisi segitiga setiap partikel memiliki enam kemungkinan arah kecepatan. Hal ini dikenal sebagai simetri heksagonal. Penggunaan segitiga sama sisi dalam model ini ternyata tidak hanya dapat memodelkan sistem yang bersifat anisotropik tetapi juga sangat memadai jika diterapkan dalam sistem yang bersifat isotropik. Bentuk segitiga sama sisi jika disusun dalam jumlah banyak akan memiliki susunan heksagonal [10].

\subsection{Persamaan Hidrodinamika LGA}

Persamaan hidrodinamika aliran fluida dari sistem banyak partikel dengan menggunakan metode Automata Gas Kisi dituliskan secara matematis sebagai berikut [8]:

$n_{i}\left(x+c_{i}, t+1\right)=n_{i}(x, t)+\Delta\left[n_{i}(x, t)\right]$

Dalam persamaan di atas $t$ merupakan integer. Nilai $n=\left(n_{1}, n_{2}, \ldots, n_{6}\right)$ ialah besaran Boolean yang menunjukkan keberadaan $\left(n_{i}=1\right)$ atau ketidakadaan $\left(n_{i}=0\right)$ partikel yang bergerak dari sebuah lokasi kisi yang terletak pada posisi $x$ ke lokasi bertetangga yang terletak pada posisi $x+c_{i}$. Operator delta $(\Delta)$ adalah operator tumbukan yang menggambarkan perubahan nilai $n_{i}(x, t)$ akibat tumbukan. Operator tumbukan ini dapat memiliki nilai 0,1 , atau -1 . Nilai ini merupakan hasil penjumlahan besaran-besaran dalam ekspresi Boolean untuk setiap tumbukan tertentu yang mungkin terjadi. Jika tidak terdapat perubahan jumlah partikel dalam arah i akibat peristiwa tumbukan, yaitu jumlah partikel sebelum dan sesudah tumbukan sama maka nilai $\Delta_{i}=1$.

Partikel bergerak dari posisi $x$ ke posisi $x+c_{i}$ dengan kecepatan satu satuan kecepatan dan arah yang diberikan oleh persamaan [8]:

$c_{i}=\left[\cos \left(\frac{2 \pi i}{6}\right), \sin \left(\frac{2 \pi i}{6}\right)\right]$

dengan $i=1,2,3,4,5$, 6. Selain memiliki enam keadaan arah kecepatan, partikel tersebut juga memiliki kemungkinan berperilaku sebagai partikel diam (rest mass).
Keenam arah kecepatan, $c_{i}, i=1,2, \ldots 6$, ditambah dengan rest mass $\left(c_{0}\right)$ ditunjukkan pada Gambar 2.1 berikut.

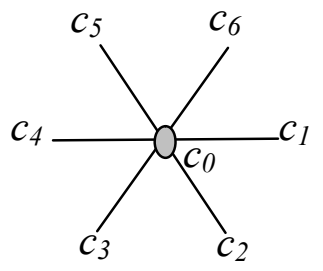

Gambar 2.1 Kisi heksagonal yang digunakan pada model FHP

Pada saat bergerak atau terjadi tumbukan dalam medium, partikel-partikel harus memenuhi hukum kekekalan massa [8]:

$\sum_{i} \Delta(n)=0$

serta harus memenuhi hukum kekekalan momentum berikut :

$\sum_{i} c_{i} \Delta_{i}(n)=0$

Dengan menggunakan persamaan (2.1), persamaan mikrodinamik untuk seluruh arah i yang menyatakan hukum kekekalan massa diberikan oleh [8]:

$\sum_{i} n_{i}\left(x+c_{i}, t+1\right)=\sum_{i} n_{i}(x, t)$

Dengan mengalikan persamaan (2.5) dengan persamaan (2.2) maka hukum kekekalan momentum akan diperoleh melalui persamaan :

$\sum_{i} c_{i} n_{i}\left(x+c_{i}, t+1\right)=\sum_{i} c_{i} n_{i}(x, t)$

Persamaan (2.5) dan (2.6) merupakan persamaan kesetimbangan massa dan momentum mikroskopik dalam sistem gas kisi yang menggambarkan evolusi massa dan momentum di dalam medan Boolean. Setiap tumbukan selalu menghasilkan konfigurasikonfigurasi tumbukan yang beragam. Sebuah momentum total yang sama dapat mengandung lebih dari satu konfigurasi dengan probabilitas kemunculan yang sama.

\subsection{Sifat Makroskopis Media Pori}

Sifat makroskopis media pori dipengaruhi oleh struktur pori. Pada umumnya sifat makroskopis media pori secara keseluruhan ditentukan oleh struktur pori medium dan tidak bergantung pada sifat-sifat lain[2].Beberapa sifat makroskopis yang dibahas dalam penelitian ini adalah tortuositas dan porositas absolut. 


\subsubsection{Porositas batuan}

Porositas didefinisikan sebagai perbandingan antara volume medium yang tidak terisi padatan dengan volume medium secara keseluruhan [4].Porositas disimbolkan dengan $\phi$ dengan satuan persen Porositas juga dapat dinyatakan dengan persamaan :

$\phi=\frac{V-V_{m}}{V}=\frac{V_{p}}{V}$

Dengan $V_{\mathrm{m}}$ adalah volume bahan padat, $V_{\mathrm{p}}$ merupakan volume pori dan $V$ adalah volume medium keseluruhan, seperti yang diperlihatkan pada gambar 2.2

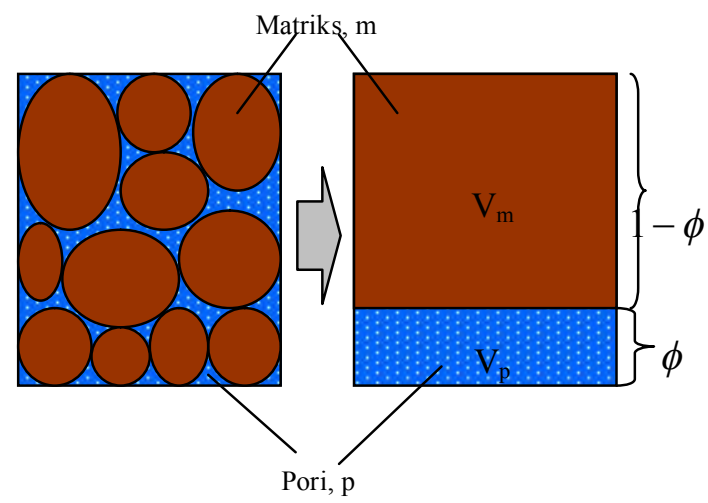

Gambar 2.2 Definisi porositas.

Pada batuan reservoir, porositas batuan dapat dibagi berdasarkan sifat-sifatnya, yaitu porositas absolut dan porositas efektif. Porositas absolut adalah perbandingan volume pori-pori total, tanpa memandang saling berhubungan atau tidak terhadap volume batuan secara keseluruhan. Porositas efektif didefinisikan sebagai perbandingan volume pori-pori yang saling berhubungan terhadap volume batuan secara keseluruhan.

\subsubsection{Tortuositas}

Tortuositas didefinisikan sebagai kuadrat rasio dari panjang lintasan efektif dalam media pori, Le (gambar II.7) terhadap panjang dari medium tempat aliran fluida, $L$, yang dinyatakan dalam persamaan berikut [2],

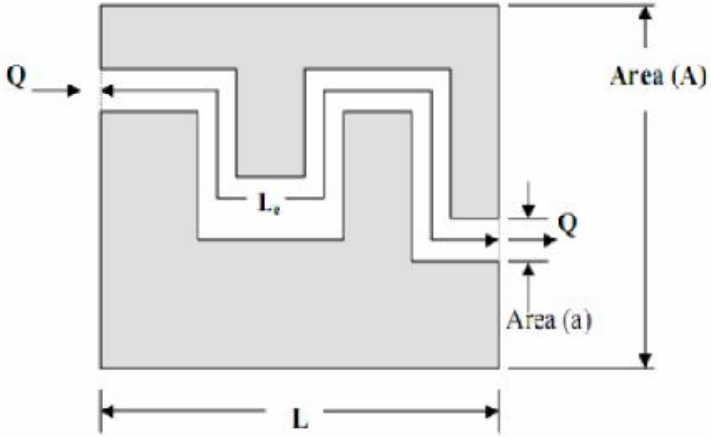

Gambar 2.3 Skema media pori[2]

$\tau=\left(\frac{L_{e}}{L}\right)^{2}$

Selanjutnya Koponen, 1996, membuat model persamaan yang dapat digunakan dalam model aliran fluida dalam media pori, yang dinyatakan dalam persamaan berikut,

$\tau=0.8(1-\phi)+1$

\section{Metode Penelitian}

\subsection{Algoritma Pemrograman}

Algoritma pemrograman untuk pemodelan aliran fluida menggunakan LGA ini dapat dijelaskan berdasarkan diagram alir sebagai berikut :

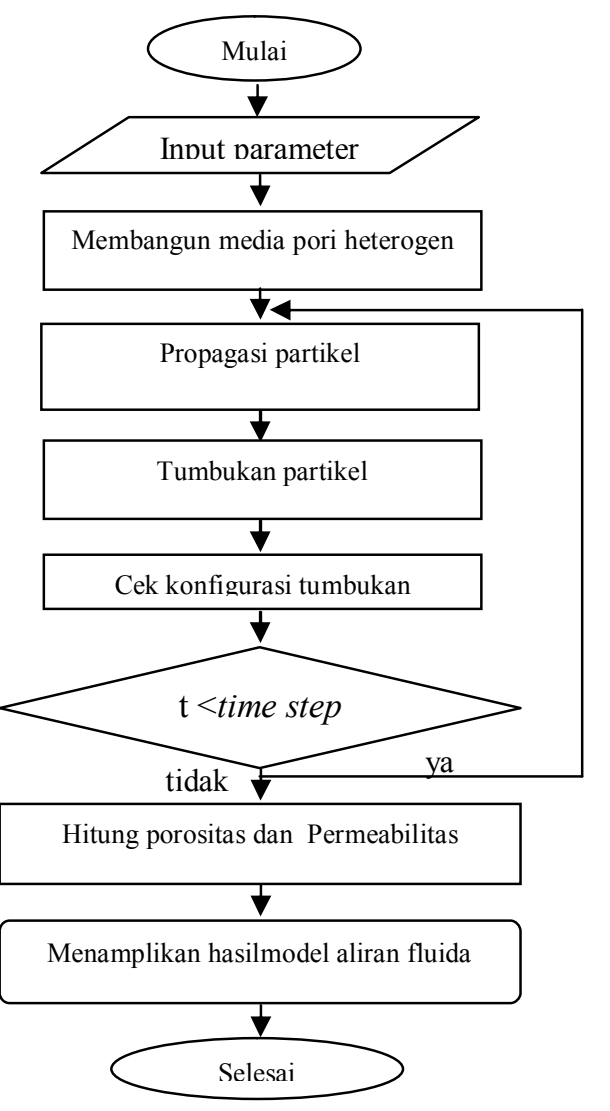




\section{Hasil dan Pembahasan}

4.1 Perbandingan HasilModelAliran Fluida melalui medium kotak

Berikut ini adalah perbandingan hasil model aliran fluida melalui medium kotak.

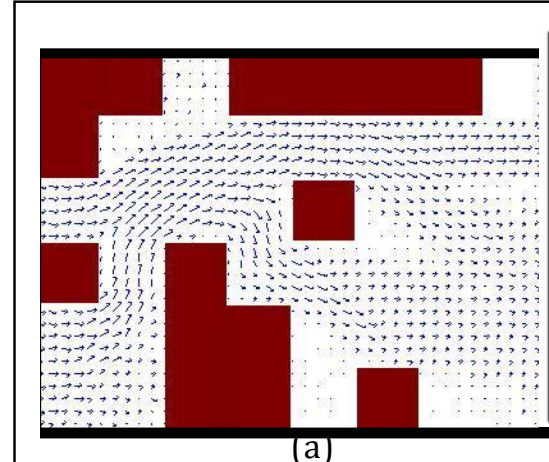

(a)

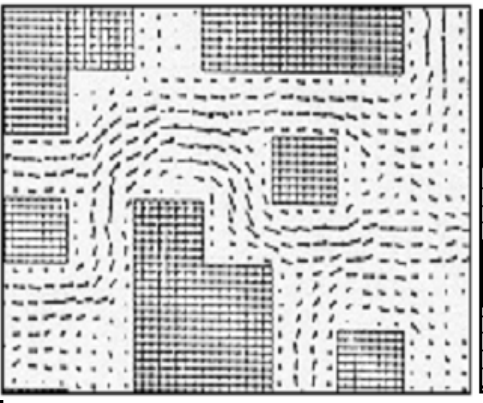

(b)

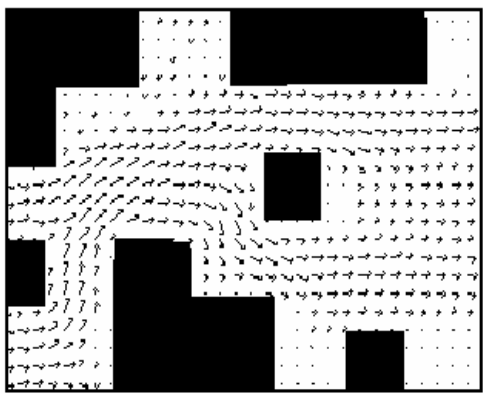

(c)

Gambar 4.1 Perbandingan hasil model aliran fluida melalui medium kotak : (a) Hasil model menggunakan FHP III dengan 2000 time steps. (b)Rothman (1997) [8], (c) Kristanto. D (2004) dengan FHP II [7].

Berdasarkan perbandingan yang terlihat pada gambar 4.1 (a), (b) dan (c) terlihat bahwa model aliran fluida yang dihasilkan dalam penelitian ini memiliki kemiripan dengan model aliran fluida yang dibuat oleh Rothman (1988) dan Kristanto (2004). Sehingga dapat disimpulkan bahwa program model aliran fluida dalam penelitian ini secara kualitatif dapat digunakan untuk menggambarkan aliran fluida dua dimensi, atau dengan kata lain, aliran fluida dalam media pori dapat dimodelkan menggunakan metoda LGA model FHP III.

\subsection{Hasil model aliran fluida melalui media pori heterogen dengan grain size $20 \mathrm{lu}$, 30 lu dan 40 lu.}

Gambar 4.2, di bawah ini menunjukan pola aliran hasil model aliran fluida melalui media pori heterogen dengan grain size $20 l u, 30 l u$ dan 40 lu. Ditampilkan juga hasil perhitungan porositas absolut (untuk seterusnya disebut porositas) dari model aliran fluida ini.

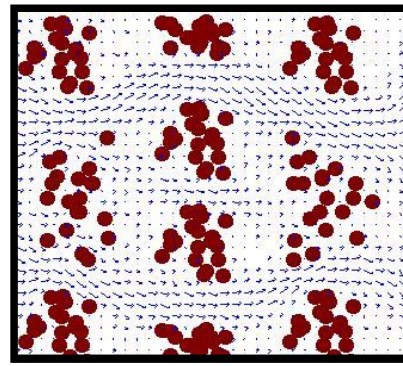

Porositas $=79.3534 \%$

(a)

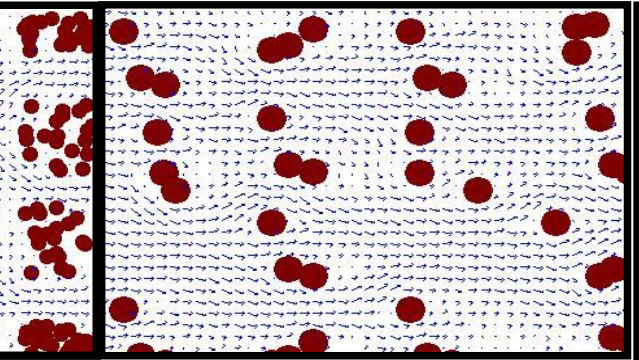

Porositas $=88.8794$

(b)

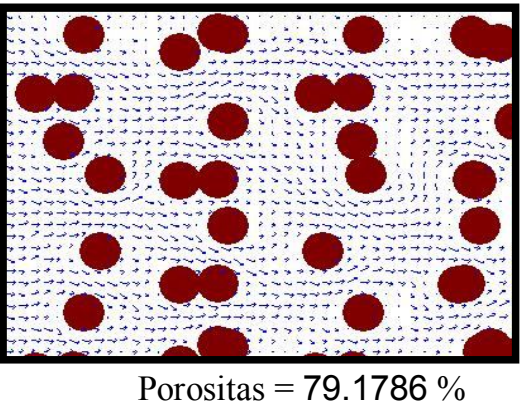

(c)

Gambar 4.2 Hasil pemodelan aliran fluida melalui media pori heterogen dengan time steps 4000, dan grain size : (a) $20 \mathrm{lu}$, (b) $30 \mathrm{lu}$ dan (c) $40 \mathrm{lu}$.

Dari gambar 4.2 secara umum terlihat bahwa :

1. Distribusi penghalang yang random telah berhasil dibuat sehingga memperlihatkan susunan media pori yang heterogen.
2. Grain size dalam penelitian ini member pengaruh terhadap nilai porositas. Grain size kecil akan menyebabkan peningkatan nilai porositas, demikian juga sebaliknya. 
3. Model yang memanfaatkan metoda LGA ini ternyata mampu menggambarkan pola aliran fluida.

\subsection{Hasil Perhitungan Sifat Makroskopis dari Media Pori Heterogen}

Perhitungan sifat makroskopis dari media pori heterogen dilakukan bersamaan dengan model aliran fluida. Hasil perhitungan sifat makroskopis tersebut dapat dilihat pada tabel 4.1 .

Tabel 4.1Hasil perhitungan nilai porositas absolut dan tortuositas dengan time steps 4000 dan grain size: (a)20 lu, (b)30 lu dan (c) 40 lu.

\begin{tabular}{|c|c|}
\hline $\begin{array}{c}\text { Porositas } \\
\text { Absolut } \\
(\phi)\end{array}$ & $\begin{array}{c}\text { Tortuositas } \\
(\tau)\end{array}$ \\
\hline 0.579853 & 1.3361 \\
0.599992 & 1.32 \\
0.649583 & 1.2803 \\
0.699433 & 1.2405 \\
0.746776 & 1.2026 \\
0.793534 & 1.1652 \\
0.840918 & 1.1273 \\
0.897542 & 1.082 \\
\hline
\end{tabular}

(a)

\begin{tabular}{|c|c|}
\hline $\begin{array}{c}\text { Porositas } \\
\text { Absolut } \\
(\phi)\end{array}$ & $\begin{array}{c}\text { Tortuositas } \\
(\tau)\end{array}$ \\
\hline 0.579314 & 1.3365 \\
0.597534 & 1.322 \\
0.641856 & 1.2865 \\
0.698575 & 1.2411 \\
0.749579 & 1.2003 \\
0.793493 & 1.1652 \\
0.844855 & 1.1241 \\
0.888794 & 1.089 \\
\hline
\end{tabular}

(b)

\begin{tabular}{|c|c|}
\hline $\begin{array}{c}\text { Porositas } \\
\text { Absolut } \\
(\phi)\end{array}$ & $\begin{array}{c}\text { Tortuositas } \\
(\tau)\end{array}$ \\
\hline 0.5744 & 1.3405 \\
0.590511 & 1.3276 \\
0.643344 & 1.2853 \\
0.69541 & 1.2437 \\
0.749325 & 1.2005 \\
0.791786 & 1.1666 \\
0.842269 & 1.1262 \\
0.885763 & 1.0914 \\
\hline
\end{tabular}

(c)
Berdasarkan persamaan-persamaan yang digunakan untuk menghitung sifat makroskopis dari media pori heterogen, terlihat bahwa porositas mempengaruhi nilai tortuositas. Berikutnya akan dijelaskan hubungan antara porositas dengan tortuositas.

\subsection{Korelasi Porositas denganTortuositas $(\tau)$}

Korelasi antara porositas dengan tortuasitas untuk grain size yang berbeda dapat dilihat dalam grafik berikut ini :

Dari gambar 4.3 (a), (b) dan (c) di atas terlihat bahwa :

1. Porositas mempengaruhi tortuositas. Semakin besar nilai porositas menyebabkan nilai tortuositas semakin kecil. Jika dihubungkan dengan hasil model pada gambar 4.2 dapat dijelaskan bahwa jika jumlah pori-pori semakin banyak maka tortuositasnya semakin kecil. Dari persamaan 2.12, yang menjelaskan hubungan antara porositas dan tortuositas, juga terlihat bahwa porositas dapat membuat berkurangnya nilai tortuositas. Sehingga dapat disimpulkan bahwa perhitungan tortuositas dalam model ini memiliki kecocokan terhadap persamaan yang menjadi dasar dari model ini.

2. Grain Size memberikan pengaruh terhadap besar kecilnya nilairtuositas. Jika dibandingkan gambar 4.3 (a), (b) dan (c) maka terlihat bahwa grain size yang lebih besar akan akan membuat nilai tortuositas juga besar. Jika dibandingkan gambar 4.3 (a), (b) dan (c) terlihat bahwa nilai tortuositas sedikit lebih besar untuk grain size 40 lu. 


\section{Penutup}

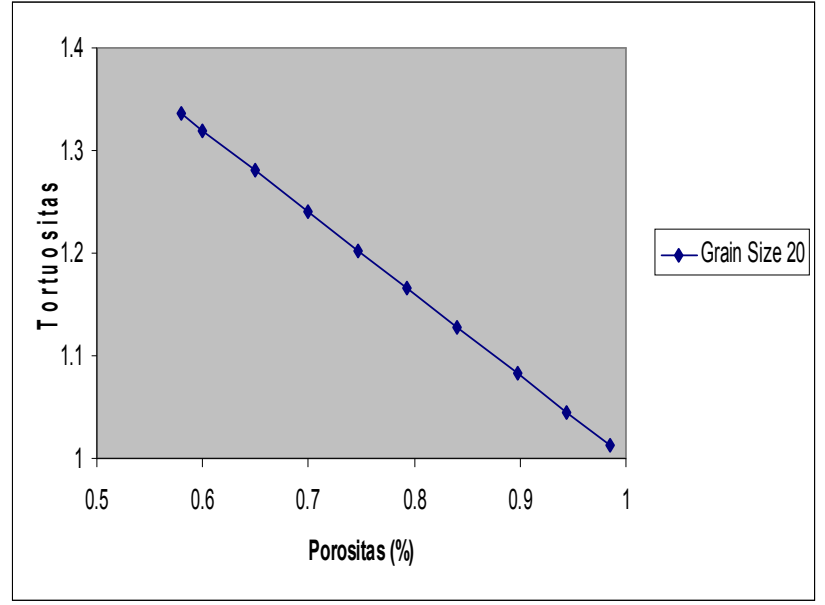

(a) Grain size $20 \mathrm{lu}$

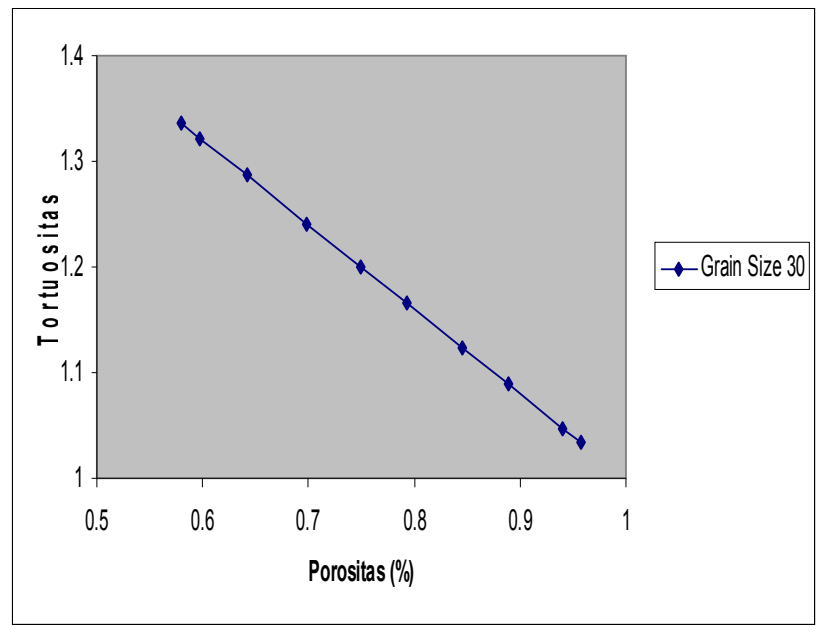

(b) Grain size 30 lu

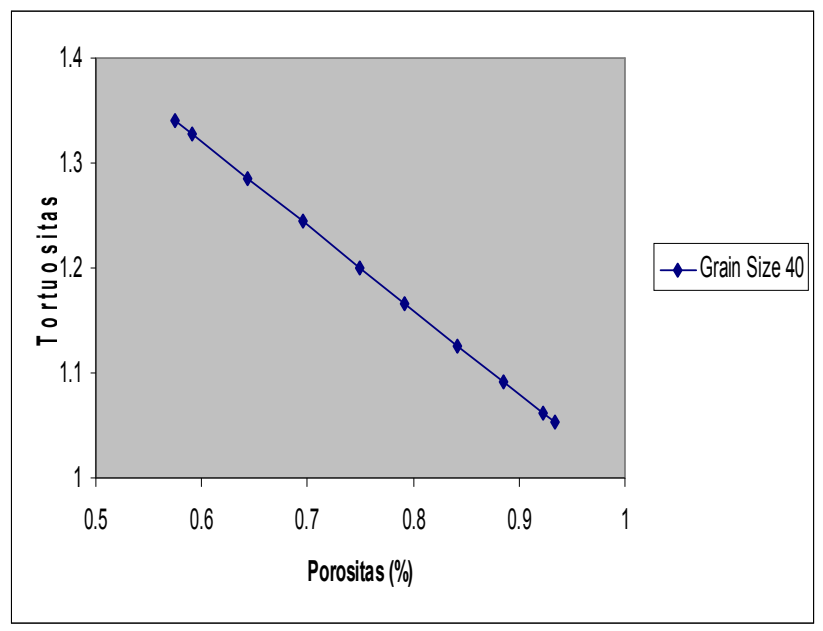

(c) Grain size 40 lu

Gambar 4.3 Hasil perhitungan tortuositas $(\tau)$ sebagai fungsi dari porositas $(\phi)$ untuk 3 grain size yang berbeda
Berdasarkan teori, hasil dan pembahasan dari model aliran fluida dalam media pori heterogen menggunakan LGA ini, maka dapat ditulis beberapa kesimpulan sebagai berikut :

1. Metoda Lattice Gas Automata (LGA) merupakan suatu metode numerik yang mampu memodelkan aliran fluida. Dengan memanfaatkan hukum kekekalan massa dan kekekalan momentum, model aliran fluida yang melewati media pori heterogen telah berhasil dibuat.

2. Pada simulasi dalam penelitian ini, sifat makroskopis dari media pori heterogen, tortuositas dan porositas absolut, dapat dipengaruhi oleh ukuran butir (grain size), jumlah penghalang dan distribusi dari penghalang pada medium aliran.

3. Nilai tortuositas berbanding terbalik dengan nilai porositas absolut.

\section{DAFTAR PUSTAKA}

[1] Dharmawan I. A., 2000, Model Automata Gas-Kisi untuk Aliran Fluida Dua Dimensi, Proceeding Komputer dan Sistem Intelijen (KOMMIT 2000), Auditorium Universitas Gunadarma, Jakarta.

[2] Dullien, F.A.L., 1979, Porous Media Fluid Transport and Pore Structure, Academic Press, New York.

[3] Frisch, U.;Hasslacher, B. and Pomeau, Y., 1986, Lattice-Gas Automata for the NavierStokes Equation. Phys. Rev. Let. 56: 15051508.

[4] Gueguen, Y. and Palciauskas, V., 1994, Introduction to The Phyisics of Rocks, Princeton University Press, Princeton.

[5] Judice, S.F.; Coutinho, B.B.S. and Giraldi, G.A., 2009, Lattice methods for fluid animation in games, ACM. Comp. in. Entr, $7: 1-29$ 
[6] Koponen, A., Kataja, M., and Timonen, J., 1997, Permeability and Porosity ofPorous Media,Phys. Rev. E., 56:3319-3325.

[7] Kristanto, D., 2004, Lattice Gas Automata Simulations of a Single-Phase and TwoPhase Flow in Heterogeneous Porous Media, Universiti Teknologi Malaysia, Malaysia, (Thesis)

[8] Rothman, D. H., and Zaleski, S., 1997, Lattice Gas Cellular Automata: Simple Models of Complex Hydrodynamics, Cambridge University Press, London.

[9] Wijaksono, A., 2005,Model aliran fluida dengan metode elemen hingga, Department of Physics, Institut Teknologi Bandung, Bandung, (Tesis).

[10] Wolf-Gladrow, D.A., 2005, Lattice-Gas Cellular Automata and Lattice Boltzmann Models - An Introduction, Springer, Germany. 